\title{
1
}

\section{Introduction: Ending the Romance of Academic Flying}

\author{
Kristian Bjørkdahl \\ and Adrian Santiago Franco Duharte
}

All the world seems to be on the move.

—Mimi Sheller and John Urry

The whole academic world seems to be on the move. Half the passengers on transatlantic flights these days are university teachers.

—David Lodge

Since the 1960s, academic work has come to be ever more closely entwined with air travel, to the point where many academics today think of flyingeven of the intercontinental variety_as an essential aspect of their work life. This situation would never have come about if it were not for the fact that 'Western societies', as Peter Adey writes, 'are made and constituted by air travel, allowing social relationships, networks and associations to be held and maintained, or conversely, to be dis-abled, destroyed, and ruined' (Adey, 2010, p. 6). International air travel, in other words, is central to our

K. Bjørkdahl $(\bowtie) \bullet A$. S. Franco Duharte

Centre for Development and the Environment, University of Oslo, Oslo, Norway e-mail: kristian.bjorkdahl@sum.uio.no; adriasf@student.hf.uio.no 
way of life, and in one sense, academics fly because that is what we all do-because, as Mimi Sheller and John Urry put it, 'All the world seems to be on the move' (Sheller \& Urry, 2006, p. 207). From another perspective, however, it is clear that academics fly for reasons that are quite distinct to them. Indeed, it would be no exaggeration to say that academics have worked aeromobility into the ethos of science, in what might appear like a peculiar mix of necessity and romance: Globetrotting is part of the allure of being an academic, but at the same time, academics must fly if they are to 'stay in the game'-or so the story goes.

In the face of the climate crisis, however, academics' infatuation with flying may increasingly come across as odd, or even absurd-not to say irresponsible (see e.g. Klöwer et al., 2020; Higham \& Font, 2020). How can academics carry on their jet-set lifestyle, when, every day, the world grows more conscious of the changes needed to avert catastrophic global warming? How can academics continue to maintain and even expand their own inclination to fly, when digital alternatives to this 'academic tourism' are becoming ever more viable as means of academic communication-not to mention how these same technologies have demonstrated their utility during the COVID-19 pandemic? And in a world that appears to be waking up-finally - to the inequities that attach to global warming, how do airborne academics justify the fact that they belong to hypermobile 'kinetic elites' (Sheller, 2018)_a class, in short, whose globetrotting rests on the involuntary sacrifices of less privileged groups?

This volume shines a light on how and why academic work became so entwined with air travel, and what can be done to change this flying habit. The starting point of the book is that flying is only one means of academic communication among many, and that the state of the planet now obliges us to shift to other means. A certain scholarly attention has been devoted to these issues over the past few years, and the present volume features contributions from several notable scholars in this area of research. The central issues of this book - why do academics fly, and what could make them reduce their flying - are more complex than they might seem, however, and we contend that existing scholarship has far from exhausted this topic.

To offer a first stab at capturing some of the issue, we will, in the remainder of this introduction, turn to the world of fiction, which might not always align with the world of research, but which is nevertheless an 
important site for exploring the complexities of human motivation. Although novelists deal in fiction, they must still present truth of some order. What they write need not be true to the events as they actually took place, but it must, on some level, be true to human experience-as some, or even many, have felt them to be. This means that we can think of the novel too as a source of knowledge about our theme.

Concerning the theme of the present book, there is no better source of fictional knowledge than David Lodge's famous campus novels, Changing Places (1975) and Small World (1984), in which the romance of academic flying is described not just with great humour, but with unparalleled precision: While these books are hilarious and over the top, they nevertheless feel true to the experience of being an academic in our time, and since our central claim here is that academics now need to reconsider their romance with flying, these satirical romances form our runway.

\section{The Holy Grail of Academic Aeromobility}

The first of these two novels begins, in fact, in mid-air, as the aerial paths of the two protagonists, Morris Zapp and Philip Swallow, meet: 'High, high above the North Pole, on the first day of 1969, two professors of English Literature approached each other at a combined velocity of 1200 miles per hour. They were protected from the thin, cold air by the pressurized cabins of two Boeing 707s, and from the risk of collision by the prudent arrangement of the international air corridors' (Lodge, 1975, p. 5). Zapp and Swallow, we learn, are on a mission to replace each other (the first travelling from Euphoric State University (read: California) to the University of Rummidge (read: Birmingham), while the other vice versa), as part of a six-month exchange scheme. Here already we have learnt something about why academics fly: Their institutions want them to - so much so, in fact, that they create elaborate and costly exchange schemes to make it happen. Admittedly, the chain of causality more likely runs in the other direction: Academic institutions desire international exchange, and exchange requires, or at least is greatly facilitated by, flying. 
At any rate, the so-called internationalisation of academia, and the various incentives that exist to increase and maintain that process, is one important reason why, as Lodge wrote, 'the whole academic world seems to be on the move' (1984, p. 459). As scholars have also pointed out, the institutional incentive of internationalisation has grown quite ubiquitous (Hopkins et al., 2016), and while it is particularly characteristic of countries like Australia and New Zealand (see Glover et al., 2019), which claim that their remoteness necessitates air travel, it is felt much more widely-for instance in the academic exchange schemes within the European Union, which have only grown since Lodge's books were published.

If institutional incentives were all there was to it, there would not be grounds for any romance of flying. As a matter of fact, though, academics possess a rich catalogue of motivations for getting up in the air and around the world — one of which is status. Again, Lodge's books provide clues: The Englishman, Swallow, is the minor academic of the two, and while he has flown before, he is anything but a frequent flyer, and hence suffers from a severe case of fear of flying. Boarding a plane, 'the sangfroid of his fellow passengers is a constant source of wonderment to him', as flying for him is 'essentially a dramatic performance' which he approaches 'like a game amateur actor determined to hold his own in the company of word-perfect professionals' (1975, p. 7). But while he feels discomfort about it, he is nevertheless forced to recognise its necessity: 'Flying is, after all, the only way to travel' (1975, p. 7). Meanwhile, Morris Zapp, the more highly reputed academic in the pair, is a 'seasoned veteran of the domestic airways, having flown over most of the states in the Union in his time, bound for conferences, lecture dates and assignations' (1975, pp. 7-8).

Frequent flying is a marker of academic success and prestige, Lodge is suggesting, while subtly underlining how flying, when done as frequently as by Morris Zapp, becomes second nature-not just a habit, but one's habitus. With a related term, Elliott and Urry (2010) talk about 'network capital', which refers not simply to a person's ability to move around and make connections to people in faraway places but to the social game in which that ability has consequences. The most typical consequence, of course, is that a globetrotting habit makes someone appear important. 
Hyper-mobility is tightly connected to elite status (Sheller 2018). This point is brought out nicely in Small World, where we also meet Arthur Kingfisher, 'doyen of the international community of literary theorists', whose highly elevated reputation stems, not least, from the fact that he is the only man in academic history to have occupied two chairs simultaneously in different continents (commuting by jet twice a week to spend Mondays to Wednesdays in Switzerland and Thursdays to Sundays in New York)' (Lodge, 1984, p. 318). The frequency of an academic's flying becomes, in other words, a direct measure of his academic status: The more you fly, the more important you are. For the most important academics of all, transcontinental flights become almost as routine as taking the underground.

Once flying comes to be connected with status, it soon becomes the source of aspiration. While Swallow is well aware that he is an amateur flyer, the mere circumstance of being in the air is quite suggestive: 'Philip Swallow, member of the academic jet-set', he thinks proudly to himself, as he boards the plane to the United States, 'ready to carry English culture to the far side of the globe at the drop of an airline ticket' (Lodge, 1975, p. 31). This is the prospect that an academic, simply by flying, will appear more important, more elevated (in the metaphorical sense) and more well reputed than those who remain on the ground. We should not assume, of course, that aspirations like the one Swallow expresses spring from hard, measurable facts. But while flying is perhaps not the direct cause of academic success, it is nevertheless a marker of the same. Some recent scholarship found, for instance, that there is no significant link between the extent of an academic's flying and their professional success, but interestingly, the same study also found that there was indeed a link between flying and salary — which underlines the point that academics' perceptions of what makes for an important academic are perhaps more important than reality.

Lodge's books are satires, of course, and hence they exaggerate. There is nevertheless a great deal of truth in them. What we find there, more specifically, is the truth of how things appear. When it comes to academic flying, these appearances are quite central, as they create a set of mutually enforcing social-professional dynamics, that work roughly so: Opportunities to fly open up more often and more readily to an 
academic who is acknowledged as important — as important scholars get more invitations to serve on panels and committees, to give key note lectures, to hold visiting professorships, and so on. If and when an academic takes advantage of such opportunities, and hence becomes a frequent flyer, this in turn sends a signal about their importance-their frequent flying tells everyone that plenty of opportunities have opened up for this particular academic, which can only be a sign that they are important, attractive and in demand. In quite a few contexts, estimations of social status in academia sidestep the question of quality, and instead fall back on an instinct that says unimportant people do not 'globetrot'.

This last point is brought home by another scene from Small World, where Morris Zapp at one point finds himself in a Rummidge taxi, on his way to (where else?) the airport. He observes the dreary, 'nearly identical three-bedroomed semi-detached houses [unwind] beside the moving cab', and these never-ending rows of depressing dwellings become an image of all that the jet-setting Morris Zapp is not:

For most of these people, today will be much like yesterday or tomorrow: the same office, the same factory, the same shopping precinct. Their lives are closed and circular, they tread a wheel of habit, their horizons are near and unchanging. To Morris Zapp such lives are unimaginable, he does not even try to imagine them; but their stasis gives zest to his mobility-it creates, as his cab speeds through the maze of streets and crescents and dual carriageways and roundabouts, a kind of psychic friction that warms him in some deep core of himself, makes him feel envied and enviable, a man for whom the curvature of the earth beckons invitingly to ever new experiences just over the horizon. (Lodge, 1984, p. 319)

This, of course, is the type of description that makes many contemporary scholars impressed by the scholarship on 'mobility justice' cringe. But however uncomfortable Morris Zapp's inner thoughts might be to ponder, flying — not exclusively for the likes of Morris Zapp, but for many lesser entities as well-has in fact become an indelible part of many academics' professional identity. If one has any academic ambitions at all, one simply has to fly; reversely, not flying is a sign that one is not succeeding. Hence, a more common affliction for academics than Philip Swallow's 
fear of flying is what some scholars have recently dubbed a 'fear of not flying': Because 'plane travel is perceived as a key driver for career progression', they write, academics are disinclined to drop their flying habit, even as they grow ever more aware that this habit is contributing to global warming (Nursey-Bray et al., 2019, p. 1). So strong is the drive to do what one believes will translate into a successful academic career, that one is prepared to discount most everything else. Or, as the fictional Morris Zapp more instinctively put it, 'the individual has to yield to the Zeitgeist or drop out of the ball game' (Lodge, 1984, p. 290).

Of course, even the Zeitgeist comes from somewhere, and when many academics today believe not just that flying is 'the only way to travel', but that such travelling is the only way to an academic career, this is due, in large part, to the availability and affordability of flying. While air travel took quite some time — and one might add, two world wars — to become established as a commercial enterprise, the trend from the early 1950s until today has been quite uniform: The price of flying is dramatically down, while the number of passenger flights is correspondingly up (Rodrigue et al., 2020). Once again, Lodge's fictions mirror the real world: In Changing Places, Philip Swallow reminisces about his honeymoon to the United States as a young man-probably in the late 1940s or early 1950s — at a time when flying was not yet 'the only way to travel': At the stay's end, he sailed home to England with his wife. In the course of the 1960s, however, flying moved from being a rare and exclusive experience to being the normal - and then the only — way to travel. From 1958 onwards, more people have crossed the Atlantic on planes than on ships, and in the 1960s, to sail across the Atlantic became a thing of the past, as the superbly fast and increasingly cheap airlines would outcompete the transatlantic ocean liners (Rodrigue et al., 2020). By the time Zapp and Swallow met in mid-air, in 1969, flying had been firmly established as a component of, one might even say a way of doing, academic work.

Since then, the idea that flying is necessary if one is to have an academic career has become ever more entrenched and appears now an almost inseparable part of what it means to be an academic. The progression from Changing Places, published in 1975, to Small World, published in 1984, provides an image of how increasingly pervasive flying would become to the academic enterprise. While the premise of the first novel 
takes off from the mobility made possible by intercontinental flight, the premise of the second is that all academics ever seem to do is travel. Small World is no longer a tale of a single trip occasioned by an internationalisation scheme but of a cast of academic characters that — quite literally_-jet around the world, from conference to conference, symposium to symposium, lecture to lecture. The narrative is modelled on the romance of the holy grail, the function of the grail in this case represented by a UNESCO chair in literary criticism, which is not just prestigious and well paid, but which is by definition mobile, 'a purely conceptual chair (except for the stipend) to be occupied where the successful candidate wished to reside'. The chair 'would have an office and secretarial staff at the Paris headquarters, but no obligation to use it. He would be encouraged to fly around the world at UNESCO's expense, attending conferences and meeting the international community of scholars, but entirely at his own discretion' (Lodge, 1984, p. 346).

One of the contenders for the chair, obviously, is Morris Zapp, who feels 'dizzy at the thought, not merely of the wealth and privilege the chair would confer on the man who occupied it, but also of the envy it would arouse in the breasts of those who did not' (1984, p. 346). At this point, Zapp has updated and refined his ideas about what it means to be a modern academic, and the category is now more or less co-extensive with that of the vagabond: 'As long as you have access to a telephone, a Xerox machine, and a conference grant fund, you're OK', Zapp explains to a young colleague, because 'you're plugged into the only university that really matters - the global campus. A young man in a hurry can see the world by conference-hopping' (Lodge, 1984, p. 269):

Because information is much more portable in the modern world than it used to be. So are people. Ergo, it's no longer necessary to hoard your information in one building, or keep your top scholars corralled in one campus. There are three things which have revolutionized academic life in the last twenty years, though very few people have woken up to the fact: jet travel, direct-dialling telephones and the Xerox machine. Scholars don't have to work in the same institution to interact, nowadays: they call each other up, or they meet at international conferences. And they don't have to grub about library stacks for data: any book or article that sounds interesting 
they have Xeroxed and read it at home. Or on the plane going to the next conference. I work mostly at home or on planes these days. (Lodge, 1984, p. 269)

Of course, direct-dialling telephones and xerox machines no longer impress anyone, but Zapp—quite accurately_points out how one consequence of these technologies were new forms of mobility, which are intertwined with what some have called 'time-space compression' (Harvey, 1990) and which others have conceptualised as 'global sense of place' (Massey, 1994). In many ways, the more recent digital technologies have simply given us more of the same, amplifying such processes even further. As an issue of the Harvard Business Review recently heralded on its front page, one of the promises of digital technologies is the 'workfrom-anywhere future' (Choudhury, 2020). This, of course, is precisely the holy grail as represented by Small World's UNESCO chair: It no longer matters where you are; you can be anywhere and everywhere, and still be doing your job.

\section{Ending the Romance}

If Lodge's books are still eminent thick descriptions of academic lifestyle, the moral universe of those books is fast acquiring a feel of being dated. The roles these books leave to women, for instance, do not hold up to today's standards: With only a couple of exceptions, almost all the academics we meet in these books are men, and while the women are presented as either housewives or vindictive wives—or, alternatively, as either prostitutes or cardboard 'love interests' - the outright suspect intentions of many of the male characters are made to seem entirely normal and excusable. The question is whether the extreme aeromobility of Lodge's academic characters can also begin to seem dated and old-fashioned. Can the academic-as-globetrotter image be made to seem a thing of the past?

That is the basic question we want to raise with this book, and it is a question which we believe is now more timely than ever (see Higham \& Font, 2020). While some of the problems with 'academic tourism' were pointed out quite a while ago (see Høyer \& Næss, 2001), a wider 
discussion about academic flying-its reasons and purposes, its consequences and ethics - has only recently begun to form. The issue has recently been the object of an unexpected boost, one might say, thanks to the COVID-19 pandemic, which 'grounded' academics, along with everyone else. That the pandemic has forced academics to reconsider their professional means of communication is clear; within a matter of days and weeks, they had begun to ponder how classes, vivas, panel meetings, seminars, workshops and even academic conferences could do without physical presence, and rely instead on digital technologies. What remains to be seen is what lasting effects the pandemic will have on academic work-if any at all.

Regardless of the pandemic, the issue of academic flying now attracts attention not only among university leadership and administration or among students and scholar-activists but also within research itselfnotably in disciplines like geography, sociology, communications and other adjacent fields, which focus on how mobility shapes contemporary society. Some of this research is closely connected to what has been called the 'new mobilities paradigm' (see the hugely influential Sheller \& Urry, 2006, and also Urry, 2000) within the social sciences, and it has recently begun to explore aeromobility as a distinct category. Books like Cwerner et al.'s Aeromobilities (2009) and Peter Adey's Aerial Life (2010) have been important in this regard. Such books have done more, though, than simply open up a new sub-field of mobilities research; they have exposed both how central and how complex the role of air travel is in our society. That said, other parts of the scholarship on academic flying have been less motivated to theorise the phenomenon and all the more set on developing practical responses to the climate crisis.

For this book, our attitude has been ecumenical. We have started from the notion that the urgency of the climate crisis presents academics with a call to confront their flying habits, and that this confrontation must include an attempt to identify pathways towards a more sustainable academic enterprise. In short, the purpose of the book is to investigate why and how we might end the romance of academic flying, in order to respond responsibly to the climate crisis. To serve this overarching purpose, we have sought contributions from scholars who engage closely with mobilities research as well as from those who do not. The result is an 
interdisciplinary book - as we believe it should be, since aeromobility shapes academic work in complex ways which extend beyond the scope of any one discipline. Our main ambition with the book has been to further the somewhat scattered scholarship that has already begun to confront academic aeromobility, so that we might help consolidate and strengthen this area of research.

The ambition to strengthen research on academic flying is in turn motivated by an idea that this research can be translated into action. While we are certainly not out to 'shame' anyone, we do believe that the present moment calls for action, and that we, given the complexity of the issue, cannot expect change to emanate from the sole efforts of any single actor. To change academia's flying habit, we will need a concerted effort along several different tracks simultaneously. For that reason, we hope that this book will contribute to sustaining interest in this topic not just among researchers but also among students, activists, research funders, university administrators and others. As the chapters that follow make very clear, academic aeromobility is no coincidence, but a form of mobility that is held up by a complex set of incentives, which over time have become entrenched as values and norms, to a point where they have come to form part of academic culture and identity. We are, in other words, up against quite the beast — and to battle it, we need all the above actors to join forces. That said, the book does contain a series of proposals for what can be done, so the perceived difficulty of the task should not keep us from starting a process of change.

\section{The Beginning of the End}

The chapters that follow fall into three main categories, which we believe represent the three analytical steps we must traverse to get a handle on the issue of academic flying. Many of the chapters in this book branch over into several of these categories, and are involved in more than one of those steps, but most place their weight within one of the following: First is the effort to document how much academics fly, and not least, what the consequences of this flying actually are. 
This effort is important not just for the sake of 'getting the facts on the table', but also to put the consequences of the academic flying habit on display, and force academics to really confront the costs of their aeromobility. This is done very effectively in Chap. 2 by Sebastian Jäckle, which aims to document the carbon footprint of academic conferences. Taking the General Conferences of the European Consortium for Political Research (ECPR) as his example, Jäckle measures the emissions from various installations of this conference across several years, revealing not just how carbon-intensive these events really are but also what difference location makes to the carbon accounts. Finally, he juxtaposes the carbon intensity of the various physical conferences with the 2020 installation of the ECPR conference, which-because of the COVID-19 pandemicwas organised as an online event. According to Jäckle's estimates, a physical instalment of the conference would, depending on the location, have had a carbon footprint between 250 and 530 times higher than the 2020 event.

A similar, yet at the same time very different, effort is presented in Chap. 3 by Mimi Sheller, who is also out to document the costs of academic aeromobility, but who focuses exclusively on her own record. With an auto-ethnographic inspiration, Sheller takes on a task that many academics would probably be disinclined to even consider: she takes stock of her own flight history. Recognising that she is indeed among the 'hypermobile' few, she re-reads her curriculum vitae as an itinerarium vitae and searches for answers to why she became such a hypermobile academic. This leads her to consider how her travels have contributed, or are complexly intertwined with, 'academic achievement'. Her itinerarium vitae, then, connects her own social mobility as an academic - the biography of how she rose in the academic ranks - to the spatial aeromobility she has engaged in during the same period. Ultimately, she too reflects on what difference the experience of being grounded by COVID-19 can make for future academic aeromobility, and urges us to begin framing the issue as one of mobility justice in the Anthropocene, which means addressing the issue of how we 'determine the distribution of the costs and benefits of long-distance travel'.

The perspective of mobility justice surfaces in several other chapters as well. For instance, in Chap. 4, Andrew Glover, Tania Lewis and Yolande 
Strengers focus on the mobilities literature and its interest in the notion of 'presence', but they turn this focus on its head, as it were, to shed light on the absences that air travel creates. They focus, in other words, on what is pushed into the background, and thereby becomes absent, as academic aeromobility creates its particular forms of presence. They highlight two such forms of 'absent presences': The first is that travel abroad necessarily means to leave one's home- and hence, to leave those with whom one shares that home. Aeromobility thus has domestic costs which are borne by those who do not travel. Another form of absence is produced when air travel becomes dissociated from the environmental impact reviews of universities as if the ambitions enhanced by the former had nothing to do with the latter-a widespread practice that allows universities to uphold two contradictory commitments.

The latter problem is dealt with in even more detail in Chap. 5 by Hans Baer. Baer takes up the discrepancy—not to say hypocrisy—of many universities that on the one hand have committed to goals of environmental sustainability and, on the other, nurture elaborate internationalisation schemes. In Australia, this conundrum is particularly acute, not just because of its remote location, but because it has done much to become a major player in higher education; this sector has become the country's third largest export industry. Baer draws on auto-ethnography from the University of Melbourne, where he has worked to expose the university's commitments, and argues that the effort to change the current hypocrisies must be framed as a struggle for social justice in which one envisages a sustainable world system quite unlike the one we currently have.

In Chap. 6, Daniel Pargman, Jarmo Laaksolahti, Elina Eriksson, Markus Robért and Aksel Biørn-Hansen again highlight the inequalities of academic flying, but they focus neither on those who stay at home nor on those who cannot afford to fly at all, nor on the environment as such, but on the unequal distribution of aeromobility between researchers themselves. Based on data from Sweden's KTH, Royal Institute of Technology, they compare the air travel of different departments - to get a better sense of exactly who flies, that is, who enjoys high levels of aeromobility and who is relatively speaking more immobile. Their data reveal substantial discrepancies between different categories of university employees, which they 
suggest are perhaps better conceptualised as 'inequalities', and which they argue exposes a need for 'discussions and negotiations about who gets to fly (or not)', and also, about what we should think of as 'unnecessary' flying. If the planet can only take a limited amount of academic aeromobility, how should that scarce resource be distributed?

If this group of chapters helpfully enriches what we understand by the 'consequences' of academic flying, by taking up effects that reach beyond those on environment, the next group of chapters takes us to another central issue, namely the issue of why academics fly. An attempt to find answers to that question is important to achieve this book's purposes, since we arguably need an appropriately sophisticated understanding of the reasons and purposes and functions of academics' flying before we can realistically contemplate alternatives to that aeromobility.

Elina Eriksson, Maria Wolrath Söderberg and Nina Wormbs in Chap. 7 argue that, if we aim to change the prevalent flying habits of academics, we cannot assume that 'more knowledge' will be enough. Research has clearly shown this recipe to be less than sufficient; people can live-and live seemingly well — within denial of climate crisis, for instance. They suggest, in contrast, that we need to understand better how academics frame and understand their own responsibility when confronted with the need for change- - how, in other words, academics reason about their own flying in the face of climate crisis. In order to discover potential for change, then, we need first to uncover academics' values and motives. Based on a survey of academics at Sweden's KTH, they discover a spectrum of different attitudes, ranging from 'climate scepticism to a commitment to radical transformation'. The survey uncovered not only what attitudes these academics currently have, thus exposing what any programme of change needs to address, it also prompted them to propose interventions, which offers another impetus for change.

Interview studies that try to ascertain the various incentives and motivations that lead academics to fly are one notable way to gain a better understanding of academic aeromobility. In Chap. 8, James Higham, Debbie Hopkins and Caroline Orchiston take up the question of what academic aeromobility offers scholars in the global periphery, in this case academics at the University of Otago, in New Zealand. Based on interviews with academics at the university, they find that four different 
themes emerge that frame and maintain these academics' flying habits. They use these themes to investigate academic resistance to change, and also take up how the disruption represented by COVID-19 might be interpreted as an opportunity for change, as a momentum from which to radically alter academics' unsustainable aeromobilities.

In Chap. 9 Lisa Jacobson takes a similar route, but her chapter is rigged more specifically to capture what difference the COVID-19 pandemic makes to the inclination to fly. She focuses especially on academics who have made a decision to reduce their flying, and in the present study, she presents interviews that add to a previous series of interviews with nonacademics who have downscaled their aeromobility. As a certain corrective to the research cited earlier, that indicates that 'more knowledge' does not help, Jacobson's previous interviews suggested that more information actually did have an impact, as it could drive someone towards a 'tipping point' of behavioural change. She also found, however, that many felt 'trapped in practices, norms and infrastructures'. For the present chapter, she interviewed academics who had already decided to reduce their flying and those who had not, but were grounded due to COVID-19. While the results largely mirrored those in the group of non-academics, the pandemic appeared - at least to those academics themselves-to represent a moment of change, as none of them believed they would return to their previous hypermobile lifestyles.

In Chap. 10, Nicholas Poggioli and Andrew Hoffman suggest that academia currently suffers from what they call flyout culture, which is 'built on a set of shared beliefs and values about the importance of flying' for academics. In an effort to outline what this culture rests on, their chapter investigates the underlying values that animate flyout culture and identifies how those values must and could change, in response to climate change. This means looking, on the one hand, at why academics currently fly as much as they do, and on the other, look at how various 'decarbonisation' schemes might affect those reasons. In a prospective exercise, they finally look at how a set of new, decarbonised, values for academia might emerge.

Poggioli and Hoffman's contribution marks the transition to the third basic question we take up with this book, and that is the effort to think through what can replace flying and how. This effort will certainly not 
come to an end with this book, but we hope at least to have provided a solid start. One might think that this will not require much of our imaginations - that it is, in fact, something of a no-brainer: 'Can't we simply switch to videoconferencing?' Some would argue that the almost immediate change of habits that was forced on us with the strictures of COVID-19 proves that videoconferencing is the future. We are not so sure. For one, as explained by the chapters described in the previous section-not to mention by David Lodge's books-flying is neither incidental nor marginal to the modern academic's lifestyle, but a central part of it. Our best bet is that this habit is going to be much harder to kick than what many now assume. Another reason why we are inclined to take the role of the sceptic here is that video might inherently be a lesser alternative; like all digital forms of communication, videoconferencing allows us to fill some of the functions of physical presence, but not all. The communication itself is often complicated, that is one thing, as everything from gestures, to turn-taking, to simultaneous speech, to various forms of response and so on get either diminished or lost entirely on video. But then there are all the other benefits to be had from travelling where video has nothing at all to offer.

These perspectives are explored further in the last group of chapters, firstly by Claus Lassen in Chap. 11, who begins by outlining how academic work is a subcategory of late modern work in general- having moved from the more static and hierarchical structures of industrial society to a mode that is 'more flexible, networked and mobile'. Aeromobility is key to many forms of such flexible work, and for academics, the perceived necessity of air travel is enhanced by ideas about the importance of face-to-face interaction. With the prospect of climate change, however, this mode of academic work has arrived at a junction, where the need for change is growing increasingly apparent and the call to take responsible choices weigh on us. For sustainable change to happen, Lassen argues, we need better ways to differentiate between ways of meeting, of what forms of presence are needed for different purposes — and that is what his chapter aims to contribute.

Birgit Schaffar and Eevi Beck likewise in Chap. 12 explore the issue of presence, and they too insist on placing this into a wider context, where the solution is perhaps somewhat less apparent than one might think. They begin by exploring what role the German thinkers who reconceptualised the university in the late eighteenth century-von Humboldt, 
Schleiermacher and Fichte-left for presence. Their concept of Erkenntnis did presume collaboration between academics, even across geographical distances, Schaffar and Beck argue, but to the extent those notions still animate academic work, they have become a problem, since academics' travel habits have become increasingly carbon-intensive. Does this mean that we can and should switch to video conferencing? The authors show how such a 'switch' resembles rather too much the technological fix, and they proceed to outline some of the complexities involved in expecting Erkenntnis to result from digital technologies. What is needed instead, they argue, is a more fundamental reconsideration of 'what research collaboration is for', and an effort to 'develop tools suited for that purpose'.

Finally, in Chap. 13, Sherry H. Y. Tseng, James Higham and Craig Lee apply the 'cultures framework' to study academic air travel. In so doing, they highlight three elements that they suggest are key to understanding why academics fly: cognitive norms, practices and material culture. This framework is, at the same time, used to suggest ways that individuals as well as institutions can identify pathways to reduce academic flying-and in this way, they suggest, the gap between theory and realities can be bridged.

\section{References}

Adey, P. (2010). Aerial life: Spaces, mobilities, affects. Wiley-Blackwell.

Choudhury, P. (2020). Our work-from-anywhere future. Harvard Business Review, November-December, 58-67.

Cwerner, S., Kesselring, S., \& Urry, J. (2009). Aeromobilities. Routledge.

Elliott, A., \& Urry, J. (2010). Mobile lives. Routledge.

Glover, A., Strengers, Y., \& Lewis, T. (2019). "Overcoming remoteness: The necessity of air travel in Australian universities", Australian Geographer, 50(4), 453-471.

Harvey, D. (1990). The condition of postmodernity. Blackwell.

Higham, J., \& Font, X. (2020). Decarbonising academia: Confronting our climate hypocrisy. Journal of Sustainable Tourism, 28(1), 1-9. https://doi.org/1 0.1080/09669582.2019.1695132

Hopkins, D., Higham, J., Tapp, S., \& Duncan, T. (2016). Academic mobility in the Anthropocene era: A comparative study of university policy at three New Zealand institutions. Journal of Sustainable Tourism, 24(3), 376-397. https:// doi.org/10.1080/09669582.2015.1071383 
Høyer, K. G., \& Næss, P. (2001). Conference tourism: A problem for the environment, as well as for research? Journal of Sustainable Tourism, 9(6), 451-470. https://doi.org/10.1080/09669580108667414

Klöwer, M., Hopkins, D., Allen, M., \& Higham, J. (2020). An analysis of ways to decarbonize conference travel after COVID-19. Nature, 583, 356-359. https://doi.org/10.1038/d41586-020-02057-2

Lodge, D. (2011 [1975]). Changing places. In The campus trilogy. Vintage Books. Lodge, D. (2011 [1984]). Small world. In The campus trilogy. Vintage Books.

Massey, D. (1994). Space, place, and gender. Polity.

Nursey-Bray, M., Palmer, R., Meyer-Mclean, B., Wanner, T., \& Birzer, C. (2019). The fear of not flying: Achieving sustainable academic plane travel in higher education based on insights from South Australia. Sustainability, 11(9), 2694. https://doi.org/10.3390/su11092694

Rodrigue, J.-P. et al. (2020). The geography of transport systems. Hofstra University, Department of Global Studies \& Geography. https://transportgeography.org Sheller, M. (2018). Mobility justice: The politics of movement in an age of extremes. London: Verso.

Sheller, M., \& Urry, J. (2006). The new mobilities paradigm. Environment and Planning A: Economy and Space, 38(2), 207-226. https://doi.org/ $10.1068 / \mathrm{a} 37268$

Urry, J. (2000). "Mobile sociology", British Journal of Sociology, 51(1), 185-203.

Open Access This chapter is licensed under the terms of the Creative Commons Attribution 4.0 International License (http://creativecommons.org/licenses/ by/4.0/), which permits use, sharing, adaptation, distribution and reproduction in any medium or format, as long as you give appropriate credit to the original author(s) and the source, provide a link to the Creative Commons licence and indicate if changes were made.

The images or other third party material in this chapter are included in the chapter's Creative Commons licence, unless indicated otherwise in a credit line to the material. If material is not included in the chapter's Creative Commons licence and your intended use is not permitted by statutory regulation or exceeds the permitted use, you will need to obtain permission directly from the copyright holder.

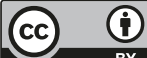

